\title{
Prevalence and risk factors for Clostridium difficile infection: a retrospective analysis
}

Mirela Indries

From The 9th Edition of the Scientific Days of the National Institute for Infectious Diseases Prof Dr Matei Bals Bucharest, Romania. 23-25 October 2013

\section{Background}

Clostridium difficile infection (CDI) is the most common cause of nosocomial infection and it is associated with increasing morbidity and mortality. The study aimed to evaluate the CDI incidence and the relapse associated risk factors in our service.

\section{Method}

This is a retrospective analysis of the cases with Clostridium difficile infection from 01 January 2012 to 31 July 2013, admitted to the Infection Diseases Department. Demographic and clinical data and risk factors (antibiotic use, underlying malignancy, chemotherapy, corticosteroids, proton-pump inhibitors - PPI - use) were noted.

\section{Results}

In the above-mentioned time span, there were 46 cases of patients with CDI. We excluded all cases where data were not sufficient to support CDI diagnosis. Out of the total cases, $58.69 \%$ were female, $54.34 \%$ from Oradea. Most cases were elderly people, 31 of them $(67.39 \%)$ over the age of 56 , and $63.04 \%$ had a recent history of surgery or in-hospital treatment. Over 32\% followed antibiotic treatment and/or PPI at home. Confirmation of the diagnosis was made by the quantitative ( 43 cases) or qualitative toxin A \& B (4 cases). There were different forms of the disease, ranging from mild gastroenteritis to colitis, pseudomembranous colitis and toxic megacolon, some with fatal outcome (1 case).Therapy included rifaximin and metronidazole (oral) for mild cases (11 cases, $23.91 \%)$, glycopeptides (oral) \pm metronidazole oral/intravenously for moderate or severe cases. There were 11 cases with recurrence (23.40\%).

Correspondence: mirela.indries@gmail.com

Municipal Clinical Hospital "Dr. Gabriel Curteanu" Oradea, Romania

\section{Conclusion}

The CDI incidence increased dramatically in our service in the first semester of 2013 compared to 2012. The prolonged hospitalization is a risk factor for the occurrence of CDI recurrence.

Published: 16 December 2013

doi:10.1186/1471-2334-13-S1-P45

Cite this article as: Indries: Prevalence and risk factors for Clostridium difficile infection: a retrospective analysis. BMC Infectious Diseases 2013 13(Suppl 1):P45.
Submit your next manuscript to BioMed Central and take full advantage of:

- Convenient online submission

- Thorough peer review

- No space constraints or color figure charges

- Immediate publication on acceptance

- Inclusion in PubMed, CAS, Scopus and Google Scholar

- Research which is freely available for redistribution
( Bīomed Central 